\title{
Health Impact Assessment of Auto Rickshaw And Cab Drivers Due To Exposure To Vehicular Pollution In Delhi: An Integrated Approach
}

Suresh Jain ( $\nabla$ sureshjain@iittp.ac.in )

Indian Institute of Technology Tirupati https://orcid.org/0000-0003-1561-3566

Vaishnavi Barthwal

Indian Institute of Technology Tirupati

\section{Research Article}

Keywords: Exposure assessment, Outdoor workers, Binary logistic regression, Respiratory problems, Occupational exposure

Posted Date: July 26th, 2021

DOI: https://doi.org/10.21203/rs.3.rs-685838/v1

License: (1) This work is licensed under a Creative Commons Attribution 4.0 International License.

Read Full License

Version of Record: A version of this preprint was published at Environmental Science and Pollution Research on August 20th, 2021. See the published version at https://doi.org/10.1007/s11356-021-160589. 


\section{Abstract}

Vehicular emission is an important contributor to air pollution in urban environment and impacts the health of commuters as well as drivers. In-vehicle concentration of pollutants is known to be higher than the ambient environment and varies with the mode of transport. Thus, this study attempts to assess the health impacts of exposure to air pollution on auto rickshaw and cab drivers. The study was conducted in Delhi using a triangular approach involving health perception survey, lung function test and in-vehicle monitoring of particulate matter $\left(\mathrm{PM}_{1}, \mathrm{PM}_{2.5}, \mathrm{PM}_{10}\right)$ concentration to assess the health impacts of air pollution on auto rickshaw and cab drivers. Total 150 respondents (75 from each occupation) were surveyed, and spirometry was performed for 40 respondents (20 from each occupation). Binary logistic regression showed auto rickshaw drivers were exposed to significantly higher in-vehicle PM concentrations in summers as well as winters and thus, had significantly higher risk of developing respiratory, ophthalmic and dermatological health symptoms $(p<0.05$ and relative risk $>1)$. Pulmonary function test showed obstructive lung impairment was reported only among auto rickshaw drivers (6\%) and restrictive lung impairment was also more prevalent among auto rickshaw drivers (48\%) than cab drivers (33\%), suggesting a greater vulnerability of auto rickshaw drivers to respiratory health issues. Lung function impairment was associated with age $(p=0.002)$. Health and wellbeing of individuals is a matter of global concern, also highlighted in sustainable development goal no. 3. However, it was observed that neither auto rickshaw drivers, nor cab drivers used formal/ standard protective measures largely due to unawareness or being unaffordable. The study suggests increasing awareness and formulate guidelines to highlight the use of proper protective measures by these vulnerable groups along with specific policy measures to protect outdoor workers like auto rickshaw drivers.

\section{Introduction}

Urban air pollution is a serious problem across the world, which directly and indirectly affects the health of a large portion of the global population especially in developing nations. It is ranked as one of the top ten causes of death by a recent study on the Global Burden of Disease (GBD) conducted by the World Health Organization (WHO); contributing to 4.2 million premature deaths every year (WHO 2018; Landrigan et al. 2017; GBD 2016). It is important to highlight that increasing concentration of air pollutants like particulate matter $(\mathrm{PM})$, ozone $\left(\mathrm{O}_{3}\right)$, carbon monoxide $(\mathrm{CO})$, oxides of sulphur $\left(\mathrm{SO}_{\mathrm{x}}\right)$, oxides of nitrogen $\left(\mathrm{NO}_{\mathrm{x}}\right)$ and volatile organic compounds (VOCs) etc. has resulted in poor air quality which affects local atmospheric visibility, built infrastructure, human health and global climate (Aggarwal and Jain 2016). Vehicular emission is an important source of air pollution in urban environment and is known to impact the health of commuters, drivers and those living on or near major or congested roads (Bowatte et al. 2018; Mindell 2017; Monrad et al. 2017; Jain et al. 2016). Samoli et al. (2016) in a study in London, found that exhaust related pollutants cause increase in the number of adult cardiovascular hospitalisations. Further, Gan et al. (2012) reported that increase in deaths due to coronary heart diseases associated with the increase in black carbon levels in Vancouver. The effects may vary with exposure duration and concentration of pollutants (Sharma and Jain 2019; Kampa and Castanas 2007). The in- 
vehicle concentration of pollutants such as PM is known to be higher than ambient environment and varied with the mode of transport (Rivas et al. 2017a, b; Jain 2017; Kumar and Gupta 2016; Apte et al. 2011). Thus, outdoor workers such as auto rickshaw, taxi and bus drivers are exposed to such high air pollution levels due to the nature of their occupation requiring long working hours' on-road or in congested areas (Zhang and Batterman, 2013). The exposure also varies with the type of transport (Jain 2017; Rivas et al. 2017; Apte et al. 2011). Ciarrocca et al. (2012) reported that traffic policemen exposed to urban traffic emissions in Italy have higher personal exposure compared to police drivers who used cars fitted with pollen filters and air conditioners for patrolling. Similarly, Zuurbier et al. (2010) reported the highest inhaled dose of pollutants among cyclists as compared to those commuting by bus or cars in Arnhem, Netherlands. Furthermore, Kumar et al. (2018) reported average $\mathrm{PM}_{2.5}$ concentrations while travelling in bus and car in Asian cities to be almost two to three times than those in European and American cities. The air quality of Indian megacities is deteriorating, leading to increased morbidity and mortality among the urban dwellers (Jain et al. 2017; Aggarwal and Jain, 2015; Sharma et al. 2013). For e.g., various studies in Delhi have reported health impacts in terms of mortality and morbidity due to the deteriorating air quality of the city (Kumar and Mishra, 2018; Bajaj et al., 2017; Aggarwal and Jain 2015). This makes outdoor workers exposed to traffic micro-environments in Delhi, a vulnerable group to severe health impacts. Bajaj et al. (2017) have reported higher relative risk of cardio-vascular and respiratory health symptoms among traffic-policemen than in the control group in New Delhi. In addition, Apte et al. (2011) reported that the in-vehicle concentration of $\mathrm{PM}_{2.5}$ and black carbon was higher in auto-rickshaws than other closed vehicles in Delhi. Thus, the present study aims to study the health impacts due to occupational exposure to urban transport microenvironment among auto rickshaw and cab drivers.

\section{Methodology}

The study used a triangular approach to assess the health impacts of occupational exposure to air pollution on auto rickshaw and cab (private taxi) drivers. It involved a cross-sectional perception survey to gather responses on health information using a structured questionnaire, along with pulmonary function test and monitoring real-time in-vehicle concentration of $\mathrm{PM}_{1}, \mathrm{PM}_{2.5}$ and $\mathrm{PM}_{10}$. Figure 1 presents the research framework used in the study. The study area was National Capital Territory of Delhi (NCT-Delhi) $\left(28.7041^{\circ} \mathrm{N}, 77.1025^{\circ} \mathrm{E}\right)$. The areas were categorised as residential, commercial and industrial areas as per the Central Pollution Control Board (CPCB) criteria (GNCTD, 2017) and sites for data collection were selected randomly from each of the strata as presented in Fig. 2.

\subsection{Data collection and statistical analysis}

A total of 150 perceptions-based surveys were conducted, which included 75 auto rickshaw drivers and 75 cab drivers that were using air-conditioned cars. The respondents were approached randomly in Delhi using a purposive approach. The data was collected during the months of April - June using a structured questionnaire to gather information about the socio-demographic information of respondents and their health perception (as explained in SI, Section S1). The health symptoms included in the questionnaire 
were related to respiratory, musculoskeletal, cardiovascular, ophthalmic, dermatological and general health symptoms based on literature review and discussion with medical experts. The survey data was analysed to determine the prevalence of various disease symptoms. Statistical analysis was done using Minitab 18. Since, the data was categorical, Chi square test was used to test the following hypotheses:

$\mathrm{H}_{0}$ : The prevalence/ occurrence of disease symptoms is same for auto rickshaw and cab drivers

$\mathrm{H}_{1}$ : The prevalence/ occurrence of respiratory symptoms is different for auto rickshaw drivers and cab drivers

$\mathrm{H}_{2}$ : The prevalence/ occurrence of ophthalmic symptoms is different for auto rickshaw drivers and cab drivers

$\mathrm{H}_{3}$ : The prevalence/ occurrence of dermatological symptoms is different for auto rickshaw drivers and cab drivers

$\mathrm{H}_{4}$ : The prevalence/ occurrence of cardiovascular symptoms is different for auto rickshaw drivers and cab drivers

$\mathrm{H}_{5}$ : The prevalence/ occurrence of musculoskeletal symptoms is different for auto rickshaw drivers and cab drivers

$\mathrm{H}_{6}$ : The prevalence/ occurrence of general health symptoms is different for auto rickshaw drivers and cab drivers

' $\mathrm{t}$ ' -test was used to compare the difference in the PM concentration inside autos and cabs during summers and winters. Association of respiratory impairment with factors such as smoking, tobacco consumption, age and body mass index (BMI) was determined using binary logistic regression (BLR).

\subsection{In-vehicle PM monitoring}

The real time in-cabin PM samples were collected using portable optical particle sizer (OPS: TSI Model3330) which records mass and number PM concentration in 10 channels of different size-range. OPS measure the PM concentration in the size-range of 0.3 to $10 \mu \mathrm{m}$ at the flow rate of $1 \mathrm{~L} / \mathrm{min}$. The readings were taken at an interval of 6 seconds for all samples. Instruments kept for in-cabin air samples were placed at the breathing height i.e.1.5ft above the seating height. Monitoring of PM was done by hiring the auto rickshaws and cabs for a commute at each time of the day which includes morning, afternoon and evening hours to take representative samples during peak and non-peak hours. PM concentrations were monitored in 15 auto rickshaws and 15 cabs (different models, makes) both during summer and winter months to get a comparative account of the seasonal variation of in- vehicle PM concentration. PM concentrations and pulmonary function tests were carried out in same auto rickshaws as well as cabs.

\subsection{Pulmonary function test}


Spirometry was used as a tool to determine physical lung function impairment. The test was conducted using Vitalograph alpha spirometer. Spirometry was performed for 20 auto rickshaws and 20 cab drivers based on their willingness and ability to perform the test (Figure S1, SI Section S2). Each subject was given a disposable mouth pieces to blow at least three acceptable manoeuvres to complete the test. FEV1, FVC and FVC/FEV1 ratio were used to interpret the lung function to be normal, restrictive or obstructive as presented in Figure S2, SI, Section S2.

\section{Results And Discussions}

Table 1 summarizes the socio demographic characteristics of the study population. Auto rickshaw drivers spend $47 \%$ of time at work while cab drivers spend $50 \%$ of the day at work and majority of respondents from both the groups ( $48 \%$ and $33 \%$, respectively) perceived the air quality at workplace to be hazardous (Figure S3 a \& b, SI, Section S3). Vehicles were considered to be the most significant pollution source as mentioned by $97 \%$ auto drivers and $88 \%$ cab drivers. Most auto rickshaw drivers perceived air quality in their residential areas to be unhealthy (26\%) while majority (30\%) of cab drivers perceived it to be hazardous (Figure S3 c \& d, SI, Section S3. Further, it is also observed that more than $85 \%$ respondents from both the groups used Liquified Petroleum Gas (LPG) as the cooking fuel. It is important to highlight that almost $50 \%$ of the sampled group both auto rickshaw and cab drivers considered air quality had a severe impact on their health (Figure S3e-f, SI, Section S3). In addition, more than half the auto rickshaw drivers and cab drivers found extreme summers to be the most difficult season as compared to extreme winters and rains in terms of health impacts and ease of work. Auto rickshaw drivers complained of headaches $(54 \%)$, rapid heartbeat $(28 \%)$, muscle cramps $(23 \%)$, while taxi drivers reported headache (33\%) and muscle cramps (12\%) during extreme summers.

Table 1: Summary statistics of socio demographic characteristics of the study population 


\begin{tabular}{|c|c|c|}
\hline Variables & Autorickshaw drivers $(\mathrm{n}=75)$ & Cab drivers $(n=75)$ \\
\hline Age (yrs.) & $39 \pm 10.52$ & $38 \pm 8.15$ \\
\hline Height (cm) & $166.5 \pm 6.64$ & $168.4 \pm 6.39$ \\
\hline Weight $(\mathrm{kg})$ & $64.8 \pm 23.35$ & $69.8 \pm 12.2$ \\
\hline BMI & $23.3 \pm 4.06$ & $24.63 \pm 4.07$ \\
\hline Smoking & $35 \%$ & $36 \%$ \\
\hline Alcohol & $33.3 \%$ & $59 \%$ \\
\hline Tobacco & $41 \%$ & $33.30 \%$ \\
\hline Working hours/day & $11.3 \pm 1.8$ & $12.11 \pm 1.8$ \\
\hline Working since & $12.82 \pm 9.28$ & $7.9 \pm 7.6$ \\
\hline \multicolumn{3}{|l|}{ Monthly income (INR) } \\
\hline $1,000-5,000$ & $0 \%$ & $0 \%$ \\
\hline $5,000-10,000$ & $13 \%$ & $4 \%$ \\
\hline $10,000-15,000$ & $37 \%$ & $19 \%$ \\
\hline $15,000-25,000$ & $40 \%$ & $28 \%$ \\
\hline$>25,000$ & $10 \%$ & $49 \%$ \\
\hline \multicolumn{3}{|l|}{ Vehicle ownership } \\
\hline Own & $53 \%$ & $63 \%$ \\
\hline Rented & $47 \%$ & $37 \%$ \\
\hline \multicolumn{3}{|l|}{ Education } \\
\hline None & $23 \%$ & $5 \%$ \\
\hline Primary & $15 \%$ & $9 \%$ \\
\hline Secondary & $30 \%$ & $39 \%$ \\
\hline Higher secondary & $23 \%$ & $35 \%$ \\
\hline Graduation and higher & $9 \%$ & $12 \%$ \\
\hline \multicolumn{3}{|l|}{ Exposure cycle } \\
\hline Home & $44 \%$ & $42 \%$ \\
\hline Work & $47 \%$ & $50 \%$ \\
\hline Outdoors & $6 \%$ & $5 \%$ \\
\hline
\end{tabular}




\subsection{In- vehicle PM concentration}

The comparative results of in-vehicle $\mathrm{PM}_{10}, \mathrm{PM}_{2.5}$ and $\mathrm{PM}_{1}$ concentrations monitored in cabs (taxies) and auto rickshaws at different times of the day, during summers and winters are presented in Fig. 3 . We found that both, auto rickshaw as well as cab drivers spent almost half of the day outdoors at work. Thus, they are exposed to high PM concentrations continuously for long durations, which is likely to cause severe health impacts over time. The average PM concentration was significantly higher $(p=$ 0.000) inside auto rickshaws as compared to cabs. Similarly, Jain (2017) reported PM exposure in nonairconditioned cars and auto rickshaws in New Delhi, was similar and showed no significant difference; while, the exposure was significantly less in airconditioned cars. Further, Okokon et al. (2018) in a study conducted in China reported very high $\mathrm{PM}_{2.5}$ concentrations $\left(256 \mu \mathrm{g} / \mathrm{m}^{3}\right)$ inside cars with windows open and air conditioning unavailable or off compared to $\mathrm{PM}_{2.5} 146 \mu \mathrm{g} / \mathrm{m}^{3}$ in cars with windows closed and air conditioning available. In a similar study, Goel et al. (2015) in New Delhi reported 30\% higher $\mathrm{PM}_{2.5}$ exposures while travelling in auto rickshaws; whereas, $50 \%$ lower exposure while travelling in airconditioned cars. Also, the in- cabin PM concentration for auto rickshaws as well as cabs was significantly higher in winters as compared to summers $(p=0.000)$. In addition, problems of episodic air pollution events in Delhi increases in winters, which necessities that proper, timely interventions are made by the concerned authorities to ensure safety of these vulnerable groups to further avoid health inequalities among outdoor exposed groups. Thus, auto rickshaw drivers can be considered more vulnerable to health issues due to PM exposure. Globally, there are no standards for in-vehicle indoor air quality except South Korea for public transport $\left(\mathrm{PM}_{10}<150 \mu \mathrm{g} / \mathrm{m}^{3}\right)$. Therefore, there is a dare need to have indoor air quality standards to save guard the human beings in various micro-environments.

\subsection{Prevalence of disease symptoms, relative risk and testing of hypotheses}

Auto rickshaw drivers had higher prevalence of all the disease symptoms as compared to cab drivers with breathlessness $(\sim 28 \%)$, eye redness $(\sim 44 \%)$, skin rashes $(22 \%)$, joint pain $(\sim 39 \%)$, irregular heartbeat and chest discomfort ( 9\%) and general weakness ( $44 \%)$ being the most prevalent respiratory, ophthalmic, dermatological, musculoskeletal, cardiovascular and general health symptoms, respectively (Fig. 4a-f). The value of relative risk greater than one for all symptoms, except common cold further suggests that auto rickshaw drivers are at relatively greater risk of developing health problems as compared to cab drivers who use airconditioned cars (Table 2). Overall, ophthalmic, musculoskeletal and general health symptoms were the most prevalent among both the groups. However, chi square test ( $\mathrm{p}$ $0.05)$, suggests that auto rickshaw drivers are significantly more susceptible to health issues may be attributed to higher exposure to transport microenvironment for all categories of disease symptoms except cardiovascular and musculoskeletal symptoms (Table 3). The p-value $>0.05$ for musculoskeletal symptoms may be because these symptoms are related to ergonomic factors and long working hours 
and both the group of workers are involved in driving for long hours (Sekkay et al. 2018). Further, PM monitoring results as explained in Sect. 3.1 showed that auto rickshaw drivers are exposed to significantly greater PM concentrations than cab drivers. In addition, vehicular emissions also contribute to VOCs, benzene, and $\mathrm{NO}_{\mathrm{x}}$ (Nagpure et al. 2017). Such traffic emissions have been associated with chronic as well as acute respiratory problems like asthma, COPD, nasal and throat irritation as well as cardiovascular health issues (Hansell et al. 2018; Lin et al. 2018; Kumar and Mishra 2018; Fisher et al. 2016). Kisku et al. (2013) reported the prevalence of eye watering ( 51\%), redness and irritation ( 33\%) and burning in eyes (20\%) among auto rickshaw drivers in Lucknow, owing to high exposure to vehicular fumes. Further, Liu et al. (2015) in Taipei, Taiwan, reported associations between exposure to traffic related $\mathrm{PM}_{2.5}$ and cardiovascular health of young adults and the effects were found to vary with the mode of commute. Exposure to PM, PAHs and black carbon is also known to aggravate various skin problems like aging, acne and skin cancer (Kim et al. 2016). 
Table 2

Relative risk of disease symptoms

\begin{tabular}{|ll|}
\hline Symptoms & Relative risk \\
\hline Sneezing & 1.82 \\
\hline Chronic cough & 1.75 \\
\hline Breathlessness & 1.46 \\
\hline Wheezing & 3.65 \\
\hline Phlegm & 2.70 \\
\hline Common cold & 0.73 \\
\hline Congestion & 1.46 \\
\hline Sore throat & 2.19 \\
\hline Eye Redness & 3.54 \\
\hline Eye irritation & 2.04 \\
\hline Blurred vision & 2.19 \\
\hline Eye burning & 2.04 \\
\hline Watering & 1.46 \\
\hline Skin rashes & 2.48 \\
\hline Skin redness & 1.82 \\
\hline Itching & 4.75 \\
\hline Chest Pain & 1.09 \\
\hline Irregular heartbeat & 5.10 \\
\hline Chest discomfort & 5.11 \\
\hline Back ache & 1.24 \\
\hline Shoulder Pain & 1.75 \\
\hline Joint pain & 1.46 \\
\hline
\end{tabular}


Table 3

Results of hypothesis testing

\begin{tabular}{|lllll|}
\hline Population & Hypothesis & $\begin{array}{l}\text { p value } \text { Chi } \\
\text { square test }\end{array}$ & $\begin{array}{l}\text { p-value Fisher } \\
\text { Exact test }\end{array}$ & $\begin{array}{l}\text { Test of null } \\
\text { hypothesis }\end{array}$ \\
\hline $\begin{array}{l}\text { Auto rickshaw drivers and } \\
\text { cab drivers }\end{array}$ & $\mathrm{H}_{1}$ & 0.002 & 0.0027 & Reject \\
\cline { 2 - 4 } & $\mathrm{H}_{2}$ & 0.00004 & 0.00005 & Reject \\
\hline $\mathrm{H}_{3}$ & 0.008 & 0.010 & Reject \\
\hline $\mathrm{H}_{4}$ & 0.065 & 0.09 & Accept \\
\hline $\mathrm{H}_{5}$ & 0.11 & 0.12 & Accept \\
\hline $\mathrm{H}_{6}$ & 0.00001 & 0.00002 & Reject \\
\hline
\end{tabular}

\subsection{Spirometry}

The results of pulmonary function tests indicated that $48 \%$ of respondents among auto rickshaw drivers as well as $33 \%$ cab drivers had restrictive lung function, while obstructive lung function was reported only for $6 \%$ of the auto rickshaw drivers and none of the cab drivers (Fig. $5 a \& b$ ). This could be because the auto rickshaw drivers had higher exposure to $\mathrm{PM}$ than cab drivers and obstructive lung function is known to be associated with exposure to pollutants like $\mathrm{NO}_{2}$ and $\mathrm{PM}_{2.5}$ and diseases such as asthma, chronic obstructive pulmonary disease and cystic fibrosis (Hansell et al. 2018; Lin et al. 2018; Fisher et al. 2016; Caronia, 2017). Restrictive pulmonary defect is associated with problems such as systemic inflammation, pulmonary fibrosis, interstitial lung disease (Johnson and Threuer 2014). Rice et al. (2015) reported significant association of chronic exposure to $\mathrm{PM}_{2.5}$ and other traffic emissions with decline in $\mathrm{FVC}$ and FEV1 values for those residing nearby major roads. Binary logistic regression (BLR) was used to test the association of lung function impairment with various factors such as age, smoking, tobacco consumption and number of years employed as auto rickshaw/ cab drivers. BLR test showed that age was significantly associated with respiratory impairment $(p=0.002)$.

\subsection{Use of protective measures}

Nearly $54 \%$ of the auto rickshaw drivers use cloth/ handkerchief to cover their face as a remedial measure while only $5 \%$ of cab drivers do so (Fig. $5 a$ \& b, SI, Section S4). These are not formal measures such as protective face masks that are specifically designed to prevent inhalation of PM and comply to standards such as the European standards, National Institute for Occupational Safety and Health standards (BS ENIOSH Guide to the Selection and Use of Particulate Respirators, 1996). Thus, such measures do not offer ample protection against PM (Noomnual and Shendell 2017; Chaschin et al. 2014; Jung et al. 2014; Langrish et al. 2012). Further, 25\% auto rickshaw drivers were unaware about which mask to be used to prevent PM exposure, from a wide range of masks such as surgical masks, quarantine masks, general masks etc. Further, nearly $19 \%$ could not afford buying proper masks owing to high cost and $10 \%$ had discomfort wearing the masks while driving. This suggests the need of 
government interventions to make appropriate safety masks economically viable and available to all. This would also help reduce health inequalities. The lesser number of cab drivers covering their face while driving was because of their perception that they are not exposed to air pollution within their vehicles.

\section{Conclusion}

It was found that auto rickshaw drivers were exposed to significantly higher PM concentrations and had a greater risk of developing various respiratory, ophthalmic, dermatological and other health problems (relative risk $>1, p<0.05$ ). The prevalence of restrictive lung impairment was higher among auto rickshaw drivers and obstruction was reported only among autorickshaw auto rickshaw drivers (6\%). This suggests causality of health symptoms with occupational exposure to traffic environment. However, current study didn't verify the symptoms with qualified doctors which can be done in future for better understanding. Further, it was observed that though auto rickshaw drivers are more exposed to vehicular emissions, they do not use proper/ standard protective measures like masks due to unawareness and discomfort in use. Thus, it is suggested that the governing bodies intervene to provide occupational health safety to these vulnerable groups through various means such as creating awareness about the health impacts of ambient air pollution and the various protective measures. This suggests that there is a need for interventions like development of guidelines on the use of standard protective measures by outdoor workers as well as commuters and making protective equipment affordable and available for all. These suggestions would also help in achieving the sustainable development goal on good health and wellbeing (SDG 3) by reducing morbidity arising from occupational exposure to air pollution.

\section{Declarations}

\subsection{Acknowledgement}

The authors would like to acknowledge the contribution of Manasvi Singha, Lady Irwin College, Delhi University for their help during data collection and compilation. We would also like to thank Mr. Ved Prakash Sharma, TERI and Mr. Govind Marwari, Maulana Azad Medical College for their technical assistance in spirometry.

Author contribution: SJ - Research concept, methodology, data analysis and manuscript writing. VB Literature review, field work, data analysis and manuscript writing

Funding: This work doesn't receive any funding from any source

Availability of data and materials: The data used in this manuscript is provided in the supplementary information. In case, further information required will be provided on request.

Ethics approval and consent to participate: Not applicable. 
Consent for publication: Not applicable.

Competing interests: The authors declare no competing interests.

\section{References}

1. Aggarwal P, Jain S (2016) Energy demand and $\mathrm{CO}_{2}$ emissions from urban on-road transport in Delhi: Current and future projections under various policy measures. J Clean Prod 128:48-61

2. Aggarwal $P$, Jain $S$ (2015) Impact of air pollutants from surface transport sources on human health: A modeling and epidemiological approach. Environ Int 83:146-157

3. Apte JS, Kirphstetter WT, Reich HA, Deshpandey SJ, Kaushik G, Phel A et al (2011) Concentrations of fine, ultrafine and black carbon particle in auto-rickshaws in New Delhi. Atmos Environ 45(26):44704480

4. Bajaj N, Sharma T, Suneja D, Jain S, Kumar P (2017) Determinants of respiratory and cardiovascular health effects in traffic policemen: A perception-based comparative analysis. J Transp Health 4:3039

5. Bowatte G, Lodge CJ, Knibbs LD, Erbas B, Perret JL, Jalaludin B, Morgan GG, Bui DS, Giles GG, Hamilton GS, Wood-Baker R (2018) Traffic related air pollution and development and persistence of asthma and low lung function. Environ Int 113:170-176

6. BS EN 529:2005 Respiratory protective devices- Recommendations for selection, use, care and maintenance- Guidance Document Available at (https://pscinitiativeorg/downloadResourceFile? resource=246\&language=en): Accessed on 4th February 2019

7. Fisher JE, Loft S, Ulrik CS, Raaschou-Nielsen O, Hertel O, Tjønneland A, Overvad K, Nieuwenhuijsen MJ, Andersen ZJ (2016) Physical activity, air pollution, and the risk of asthma and chronic obstructive pulmonary disease. Am J Respir Crit Care Med 194(7):855-865

8. GBD (2016) Burden of disease from ambient air pollution for 2016 Available at http://wwwwhoint/airpollution/data/AAP_BoD_results_May2018_finalpdf: Accessed 28th August 2020

9. Goel R, Gani S, Guttikunda SK, Wilson D, Tiwari G (2015) On-road PM2 5 pollution exposure in multiple transport microenvironments in Delhi. Atmos Environ 123:129-138

10. Hansell A, Doiron D, Probst-Hensch Ne, de Hoogh K (2018) Associations Between Ambient Air Pollution Exposure, Lung Function and COPD: Results from the UK Biobank Cohort. Am J Respir Crit Care Med 197:A7719

11. Jain S (2017) Exposure to in-vehicle respirable particulate matter in passenger vehicles under different ventilation conditions and seasons. Sustainable Environ Res 27:87-94

12. Jain S, Aggarwal P, Sharma P, Kumar P (2016) Vehicular exhaust emissions under current and alternative future policy measures for megacity Delhi, India. J Transp Health 3(3):404-412 
13. Jung H, Kim J, Lee S, Lee J, Kim J, Tsai P, Yoon C (2014) Comparison of filtration efficiency and pressure drop in anti-yellow sand masks, quarantine masks, medical masks, general masks, and handkerchiefs. Aerosol Air Qual Res 14(14):991-1002

14. Kampa M, Castanas E (2007) Human Health effects of air pollution. Environ Pollut 151:362-367

15. Kim KE, Cho D, Park HJ (2016) Air pollution and skin diseases: adverse effects of airborne particulate matter on various skin diseases. Life Sci 152:126-134

16. Kisku GC, Pradhan S, Khan AH, Bhargava SK (2013) Pollution in Lucknow City and its health implication on exposed vendors, drivers and traffic policemen. Air Qual Atmos Health 6(2):509-515

17. Kumar A, Mishra RK (2018) Human health risk assessment of major air pollutants at transport corridors of Delhi, India. J Transp Health 10:132-143

18. Kumar P, Gupta NC (2016) Commuter exposure to inhalable, thoracic and alveolic particles in various transportation modes in Delhi. Sci Total Environ 541:535-541

19. Kumar P, Patton AP, Durant JL, Frey HC (2018) A review of factors impacting exposure to $P M_{25}$, ultrafine particles and black carbon in Asian transport. microenvironments Atmos Environ 187:301316

20. Manuela C, Francesco T, Tiziana C, Assunta C, Lara S, Nadia N, Giorgia A, Barbara S, Maria F, Carlotta C, Pia SM (2012) Environmental and biological monitoring of benzene in traffic policemen, police drivers and rural outdoor male workers. J Environ Monit 14(6):1542-1550

21. Landrigan PJ, Fuller R, Acosta NJR, Adeyi O, Arnold R, Basu NN et al (2017) The Lancet Commission on pollution and health. Lancet 391:1-51

22. Langrish JP, Li X, Wang S, Lee MM, Barnes GD, Miller MR, Cassee FR, Boon NA, Donaldson K, Li J, Li $L$ (2012) Reducing personal exposure to particulate air pollution improves cardiovascular health in patients with coronary heart disease. Environ Health Perspect 120(3):367-372

23. Lin H, Qian ZM, Guo Y, Zheng Y, Ai S, Hang J, Wang X, Zhang L, Liu T, Guan W, Li X (2018) The attributable risk of chronic obstructive pulmonary disease due to ambient fine particulate pollution among older adults. Environ Int 113:143-148

24. Liu WT, Ma CM, Liu IJ, Han BC, Chuang HC, Chuang KJ (2015) Effects of commuting mode on air pollution exposure and cardiovascular health among young adults in Taipei, Taiwan. Int $\mathrm{J}$ Hyg Environ Health 218(3):319-323

25. Mindell JS (2017) Transport and health around the world. J Transp Health 4:1-3

26. Monrad M, Sajadieh A, Christensen JS, Ketzel M, Raaschou-Nielsen O, Tjønneland A, Overvad K, Loft S, Sørensen M (2017) Long-term exposure to traffic-related air pollution and risk of incident atrial fibrillation: a cohort study. Environ Health Perspect 125(3):422-427

27. Nagpure AS, Gurjar BR, Kumar V, Kumar P (2016) Estimation of exhaust and non-exhaust gaseous, particulate matter and air toxics emissions from on-road vehicles in Delhi. Atmos Environ 127:118124 
28. NIOSH Guide to the Selection and Use of Particulate Respirators (1996) DHHS (NIOSH) Publication Number 96-101 Available at https://wwwcdcgov/niosh/docs/96-101/defaulthtml Accessed 4th February 2021

29. Noomnual S, Shendell DG (2017) Young Adult Street Vendors and Adverse Respiratory Health Outcomes in Bangkok, Thailand. Saf Health Work 8(4):407-409

30. Okokon EO, Taimisto P, Turunen AW, Amoda OA, Fasasi AE, Adeyemi LG et al (2018) Particulate air pollution and noise: Assessing commuter exposure in Africa's most populous city. J Transp Health 9:150-160

31. Rice MB, Ljungman PL, Wilker EH, Dorans KS, Gold DR, Schwartz J et al (2015) Long-term exposure to traffic emissions and fine particulate matter and lung function decline in the Framingham heart study. Am J Respir Crit Care Med 191(6):656-664

32. Rivas I, Kumar P, Hagen-Zanker A (2017) Exposure to air pollutants during commuting in London: are there inequalities among different socio-economic groups? Environ Int 101:143-157

33. Rivas I, Kumar P, Hagen-Zanker A, de Fatima Andrade M, Slovic AD, Pritchard JP, Geurs KT (2017) Determinants of black carbon, particle mass and number concentrations in London transport microenvironments. Atmos Environ 161:247-262

34. Sekkay F, Imbeau D, Chinniah Y, Dubé PA, de Marcellis-Warin N, Beauregard N, Trépanier M (2018) Risk factors associated with self-reported musculoskeletal pain among short and long distance industrial gas delivery truck drivers. Appl Ergon 72:69-87

35. Samoli E, Atkinson RW, Analitis A, Fuller GW, Green DC, Mudway I, Anderson HR, Kelly FJ (2016) Associations of short-term exposure to traffic-related air pollution with cardiovascular and respiratory hospital admissions in London, UK. Occup Environ Med 73(5):300-307

36. Sharma D, Jain S (2019) Impact of intervention of biomass cookstove technologies and kitchen characteristics on indoor air quality and human exposure in rural settings of India. Environ Int 123:240-255

37. Sharma P, Sharma P, Jain S, Kumar P (2013) An integrated statistical approach for evaluating the exceedence of criteria pollutants in the ambient air of megacity. Delhi Atmos Environ 70:7-17

38. WHO (2018) Ambient air pollution: Health impacts Available at http://wwwwhoint/airpollution/ambient/health-impacts/en/ Accessed 24th August 2020

39. Zhang K, Batterman S (2013) Air pollution and health risks due to vehicle traffic. Sci Total Environ 450:307-316

40. Zuurbier M, Hoek G, Oldenwening M, Lenters V, Meliefste K, van den Hazel P, Brunekreef B (2010) Commuters' exposure to particulate matter air pollution is affected by mode of transport, fuel type, and route. Environ Health Perspect 118(6):783-789

\section{Figures}




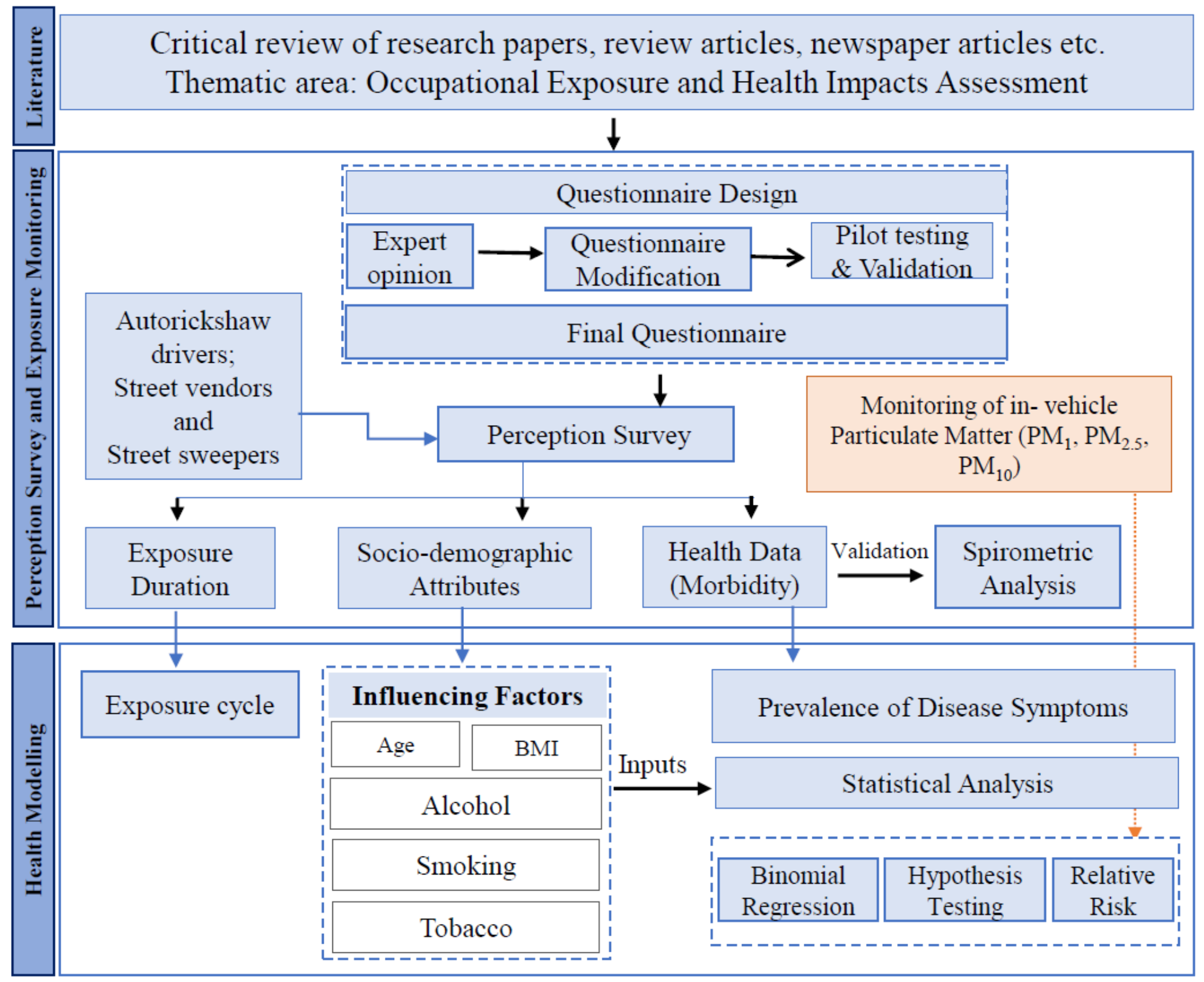

\section{Health Impacts (Impact of Influencing factors on prevalence of disease symptoms)}

\section{Figure 1}

Methodological framework for health impact assessment of auto rickshaw drivers and cab drivers 


\begin{tabular}{|l|l|}
\hline 138 \\
AREAS
\end{tabular}

Figure 2

Map of study area showing the locations of health survey 


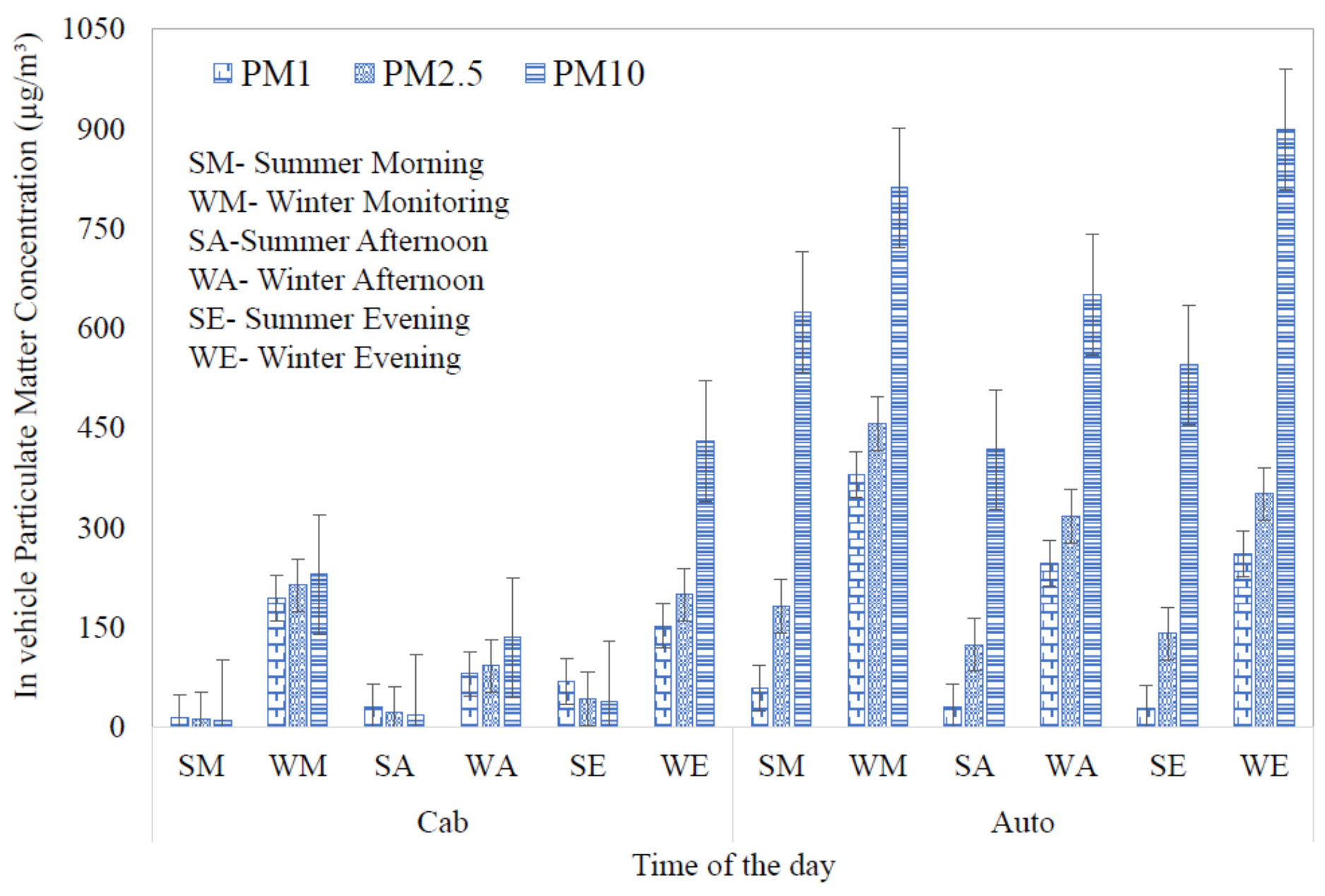

Figure 3

Comparison of In vehicle concentration of Particulate Matter 
(a) Respiratory symptoms

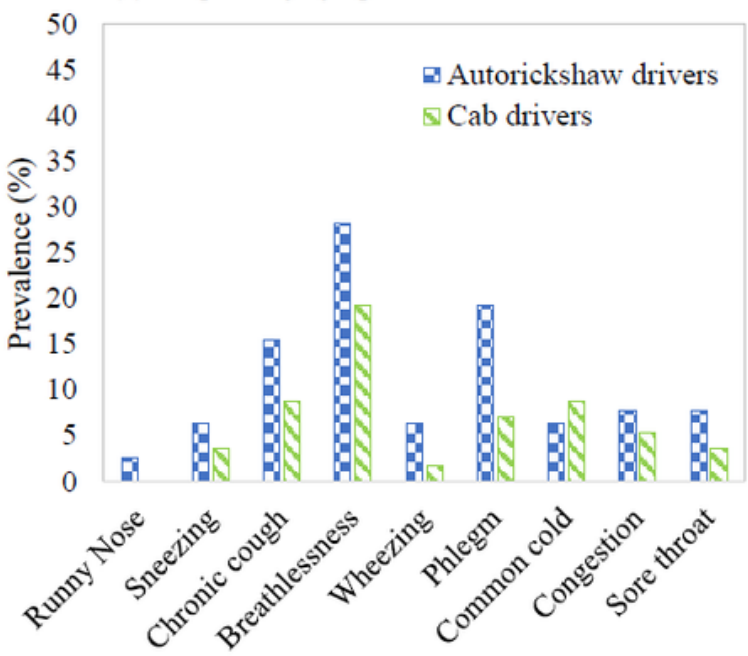

(c) Dermatological symptoms

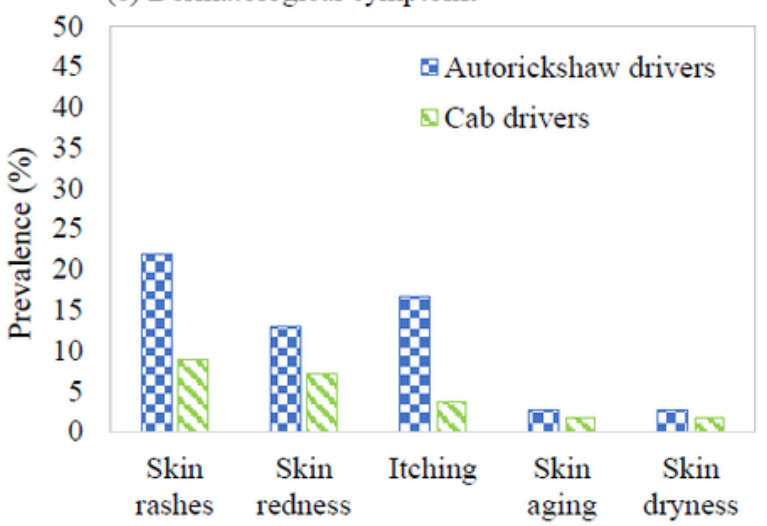

(e) Cardiovascular symptoms

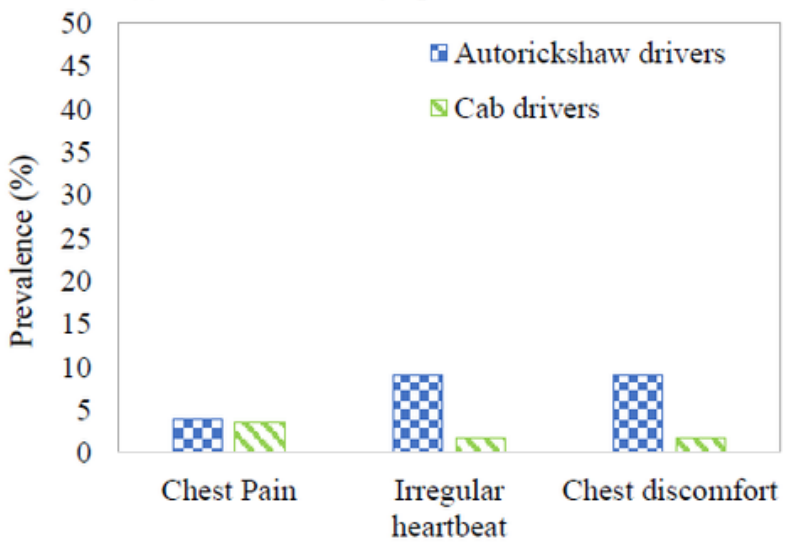

(b) Ophthalmic symptoms

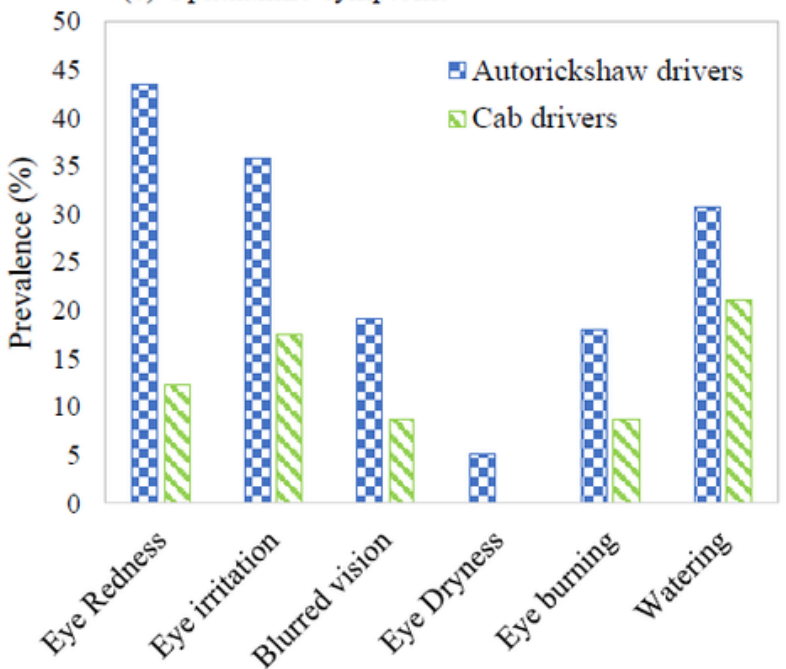

(d) Musculoskeletal symptoms

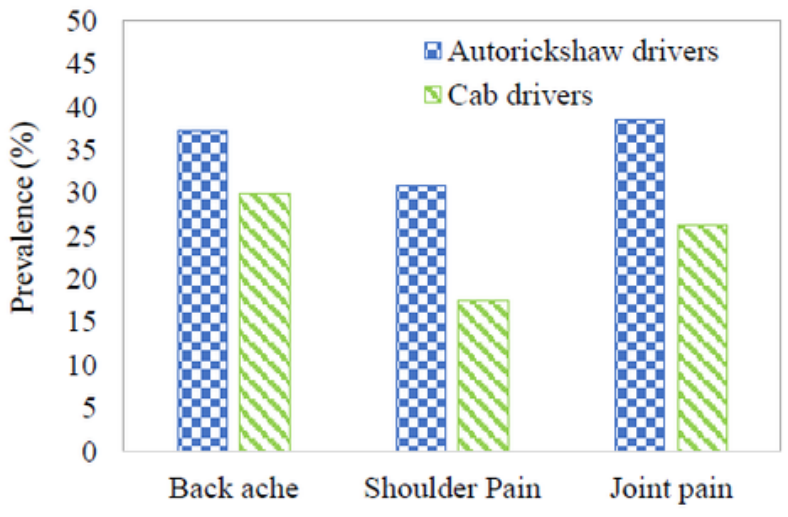

(f) General health symptoms

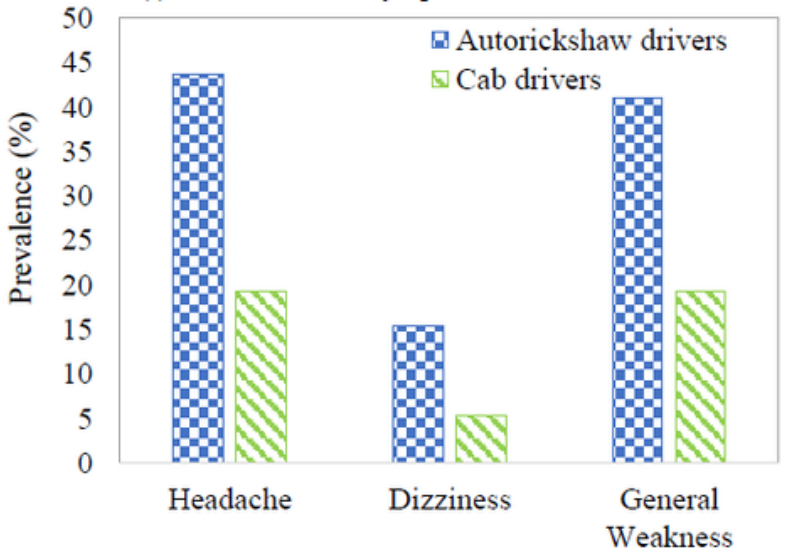

\section{Figure 4}

Prevalence of disease symptoms among autorickshaw drivers and cab drivers 

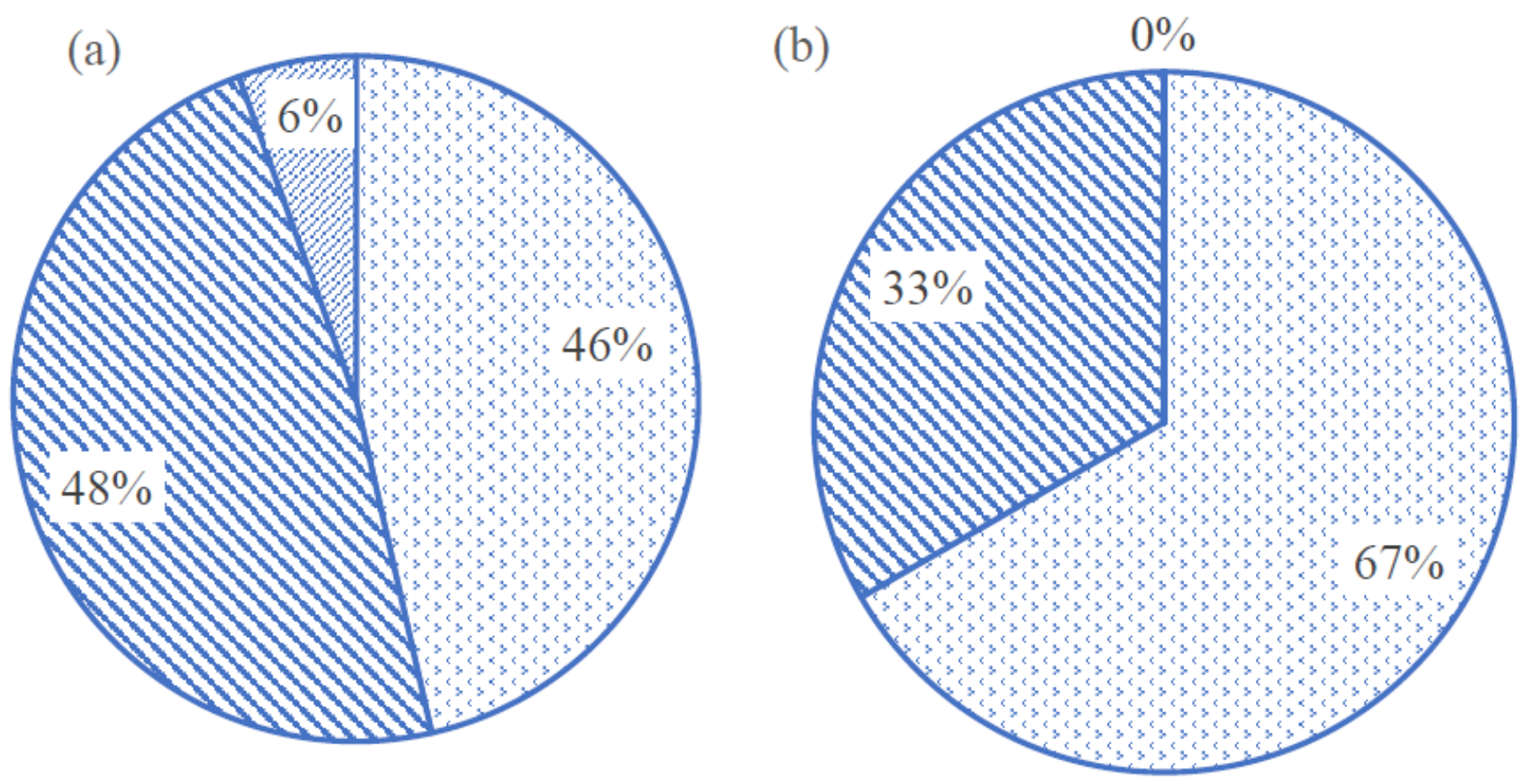

DNormal $\mathbf{\Delta R e s t r i c t i o n ~} \boldsymbol{\nabla}$ Obstruction

\section{Figure 5}

Lung function (a) Autorickshaw drivers (b) Cab drivers

\section{Supplementary Files}

This is a list of supplementary files associated with this preprint. Click to download.

- SupplementaryInformationAutoCabDriversF.docx 